\title{
Into the Twenty-First Century: Medical History Goes Online
}

As of spring 2005, Medical History became the first medical history journal to make its complete archive available, free of charge, on the Internet. All future issues of Medical History will be freely available online at the time of publication. The journal will continue to be produced and be available in hard copy, and we hope that our readers will enjoy and make use of the flexibility of these parallel publication formats. The open access online is in close accord with the Wellcome Trust's declared position on the desirability of open access to scientific literature, and we, as editors, are proud to have been able to take this pioneering initiative. The project was masterminded by Robert Kiley of the Wellcome Library and Martha Fishel at the National Library of Medicine, to whom we are greatly indebted. Medical History was released into PubMed Central as part of a $£ 1.2$ million collaborative project between the Wellcome Trust, the Joint Information Committee and the US National Library of Medicine. Other titles that will come online over the next few months include the Biochemical Journal, the Journal of Physiology, the Journal of Anatomy and the British Journal of General Practice. In total, the project aims to deliver two million pages of text from a dozen or so important and historically significant medical journals. In addition to creating a new digital copy of every page in the backfiles, the digitisation process also creates a PDF file for every discrete item (article, editorial, letter, advertisements etc) in the archive, and uses optical character recognition technology to generate searchable text. Other features include the provision of separate, high resolution scans for every image or figure in the archive and the inclusion of context-sensitive online corrections. This permits corrections to previously-published articles, and if these are made PubMedCentral provides a link from the original article to the online correction.

The complete archive of Medical History can be found at: http://www.pubmedcentral. gov/

Further information on the project, including a list of journals which have agreed to participate, can be found at: http://library.wellcome.ac.uk/backfiles

Harold J Cook and Anne Hardy 